\title{
CRECEMENTO E EXPANSIÓN DOS SERVIZOS DE TELECOMUNICACIÓNS EN ARXENTINA DURANTE A POSCONVERTIBILIDADE: CONCENTRACIÓN ECONÓMICA CON DESCENTRALIZACIÓN PRODUTIVA?
}

Martín RODRÍGUEZ-MIGLIO1

Resumo: Neste traballo analizamos o desempeño económico e laboral recente do sector dos servizos de telecomunicacións en Arxentina, dende a saída da crise de convertibilidade ata 2013, a partir da evolución da produción, participación, emprego, remuneracións e produtividade.

Abstract: Growth and expansión of the Telecommunications sector in Argentina during the Post-Convertibility period: Economic concentration with productive decentralization?

Palabras chave: Servizos de telecomunicacións

\section{1- Introdución}

A revolución nas telecomunicacións nos anos recentes non só xerou grandes cambios na forma de comunicarnos en termos persoais, senón que tamén foi protagonista de fortes cambios económicos, produtivos, organizacionais, etc. O crecente caudal de voces, datos, imaxes que circulan na actualidade modificou os nosos hábitos, asemade que manifestou a emerxencia de novos produtos y servizos, como a telefonía móbil ou os servizos de internet. Estes servizos acadaron un alto nivel de masificación superando nalgúns casos o grao de penetración na poboación. Hoxe en día en moitos países a cantidade de servizos móbiles supera á poboación local acadando unha distribución maior a un móbil por habitante. A nivel mundial o sector das telecomunicacións gañou relevancia na estrutura produtiva, e isto é así non só polo uso doméstico ou persoal que asumen estes servizos, senón que tamén pola posibilidade de potenciar as distintas actividades produtivas onde as novas tecnoloxías da información e comunicación se aplican.

En Arxentina esta revolución tecnolóxica impactou economicamente de par do acontecido a nivel mundial. Nos últimos anos a produción de servizos de telecomunicacións diversificouse, a súa facturación multiplicouse e o valor agregado sectorial gañou participación na estrutura produtiva local (Rodríguez Miglio e Delfini, 2015). Na actualidade operan arredor de 12 grandes empresas de telefonía fixa, móbil e transmisión de datos en Internet, xunto a un amplo mercado de pemes que ofrecen principalmente servizos de transmisión de datos. As vendas do sector representan arredor do 3\% do VAB nacional e, en termos de emprego, o sector xera na actualidade máis de 75 mil postos de traballo (INET, 2010). As dúas maiores empresas do sector son Telefónica de Argentina e Telecom Argentina, que ademais se atopan dentro das 10 empresas de maior facturación que operan na economía local (Revista Mercado, 2014).

Neste traballo analizaremos o desempeño económico e laboral recente deste sector, dende a saída da crise de convertibilidade ata 2013, a partir da evolución da produción, participación, emprego, remuneracións e produtividade. Na primera sección abordarase o tema de maneira agregada a partir de datos oficiais e información de cámara, para despois avanzar na segunda sección coa análise dunha empresa significativa que opera neste sector, a partir da información da contabilidade que xorde dos seus balances. A través deste exercicio de análise a dous niveis pretendemos contribuír coa caracterización do sector e o seu desempeño na etapa recente e identificar as potencialidades e limitacións ás que se enfrontan. A última sección do documento rescata algunhas reflexións que xurdiron a partir da elaboración do mesmo e enuncíanse algunhas preguntas que xurdiron desta análise, para profundar coa caracterización.

${ }^{1}$ Instituto de Industria, Universidad Nacional de General Sarmiento, Arxentina. mrmiglio@ungs.edu.ar 


\section{Desempeño económico recente do sector telecomunicacións}

A economía Arxentina experimentou un forte ciclo de crecemento a partir da saída da convertibilidade no ano 2002. Este crecemento do valor agregado implicou elevar os niveis de emprego que foran fortemente deteriorados nos anos anteriores, principalmente no ocaso do rexime de convertibilidade (1991-2001). A recuperación das principais variables macro da economía Arxentina estimulou o debate sobre a posibilidade dun cambio estrutural na economía local. Así, diversas opinións oscilaron entre o rexeitamento desta tese e a matización do devandito cambio (Azpiazu e Schorr, 2010; Santarcángelo et al, 2011; Lavopa e Muller, 2009; Roitter et al, 2010). Ao noso xuízo, un dos elementos que impediría pronunciarse a favor dun cambio radical da estrutura económica Arxentina está relacionado coa distribución da produción entre tres grandes sectores produtivos, a saber, Servizos, Industria manufactureira e Resto dos bens. Ao observar esta distribución entre a etapa previa e a posterior á convertibilidade resulta notorio a forte concentración da produción no sector servizos ao longo de todo o período, acadando niveis superiores ao $60 \%$ do PBI (Rodríguez Miglio e Delfini, 2015). A persistencia dunha economía que conserva un forte rasgo da produción orientada aos servizos rexeita a tese de reindustrialización defendida dende algúns sectores e pon en evidencia a necesidade de observar a súa dinámica particular.

A nivel mundial o sector terciario é o máis importante en termos de participación (arredor do 80\%) nas economías que deteñen os maiores niveis de ingresos como o Reino Unido, Estados Unidos ou Luxemburgo. Segundo a Cámara Arxentina de Comercio, no noso país a produción atópase orientada cara aos servizos nun nivel próximo ao 70\%. O emprego rexistrado exhibe a mesma tendencia cara á concentración no sector terciario (CAC, 2010). Localmente entre os anos 1993 e 2003, o sector terciario avanzou na súa participación movéndose dende un $60 \%$ ata os case $70 \%$ da actualidade. Está tendencia non se reverteu sequera transitoriamente nos anos da crise (2001/ 2002). Entre a grande heteroxeneidade de actividades que están contidas neste sector en Arxentina destacan tres: comercio (22\%), transporte e comunicacións (19\%) e actividades inmobiliarias e empresariais (18\%). Así, entre estas tres actividades explícase preto do $60 \%$ da produción total de servizos do país (Rodríguez Miglio e Delfini, 2015).

As telecomunicacións arxentinas destacan nesta fase de crecemento por diversas cuestións. Esta industria presenta un forte dinamismo a partir da saída da crise de 2001/2002, o cal é evidente polo crecemento das vendas do sector. En termos nominais, despois dunha caída da orde do $30 \%$ durante os anos da crise, as vendas recuperáronse rapidamente a partir do seguinte ano acadando unha taxa de crecemento media de preto do $25 \%$ anual. Cara o ano 2004 o sector xa se atopaba en niveis de vendas superiores ao momento de ocaso da convertibilidade (Táboa 1). Porén, dado que a presenza do capital transnacional no sector reviste unha significativa importancia, corresponde analizar o ocorrido dende o punto de vista económico do actor estranxeiro. Así, observamos que a evolución das vendas en dólares sofreu os efectos da crise por un período un poco máis alongado que o evidenciado en termos da evolución en moeda local.

A saída da convertibilidade e a consecuente devaluación do peso impactaron deteriorando en case un $80 \%$ o volume de vendas das telecomunicacións medido en dólares. Este volume de vendas, malia que comezou a súa recomposición tamén a partir do ano 2003, tivo que agardar ata 2010 para achegarse aos niveis previos á crise. Así mesmo, aínda a partir de 2011 todos os anos exhiben valores superiores aos de 2001, o crecemento en vendas foise desacelerando tornándose negativo nos últimos dous anos analizados. Esta dificultade para a obtención dun maior volume de vendas en dólares podería implicar a priori, para as empresas estranxeiras que operan no sector, unha diminución da súa rendibilidade 
considerada globalmente. Retomaremos a mirada sobre a rendibilidade no seguinte apartado.

Táboa 1. Evolución das vendas do sector telecomunicacións , 2001-2014

\begin{tabular}{l|cc}
\multicolumn{1}{c}{ ANO } & vendas en millóns de pesos & vendas en millóns de dólares \\
\hline $\mathbf{2 0 0 1}$ & 10.810 & 10.810 \\
$\mathbf{2 0 0 2}$ & 7.550 & 2.247 \\
$\mathbf{2 0 0 3}$ & 8.885 & 3.032 \\
$\mathbf{2 0 0 4}$ & 13.060 & 4.397 \\
$\mathbf{2 0 0 5}$ & 15.660 & 5.168 \\
$\mathbf{2 0 0 6}$ & 19.100 & 6.242 \\
$\mathbf{2 0 0 7}$ & 24.055 & 7.637 \\
$\mathbf{2 0 0 8}$ & 29.600 & 8.580 \\
$\mathbf{2 0 0 9}$ & 33.000 & 8.707 \\
$\mathbf{2 0 1 0}$ & 39.081 & 9.844 \\
$\mathbf{2 0 1 1}$ & 52.265 & 12.155 \\
$\mathbf{2 0 1 2}$ & 68.098 & 13.869 \\
$\mathbf{2 0 1 3}$ & 82.971 & 12.765 \\
$\mathbf{2 0 1 4}$ & 100.428 & 11.746
\end{tabular}

Fonte: Elaboración propia en base a CICOMRA

Con relación á estrutura produtiva local, o sector recuperou a participación na produción de valor agregado ata o ano 2009, momento no que manifestou un leve retroceso (entre 2010 e 2011) para despois recuperarse de novo en 2012. Porén, esta participación permanece aínda por debaixo do ano 2009, ano de maior participación (Gráfico 1). Malia que a información analizada non permite diferenciar o movemento entre transporte e comunicación, a presente tendencia e a evolución das vendas comentada máis arriba (moi por enriba do crecemento medio nacional) permiten supoñer que no ámbito específico das telecomunicacións o desempeño se atopa preto da tendencia da serie.

Gráfico 1. Participación relativa do sector telecomunicacións no VAB Nacional
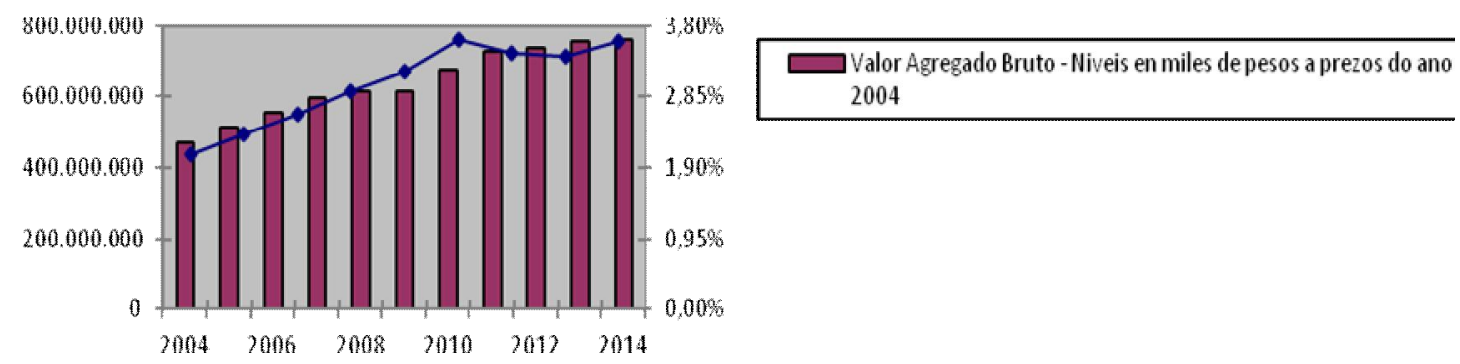

Fonte: Elaboración propia en base a Indec

A produción das telecomunicacións contempla tanto a telefonía fixa como móbil, a transmisión de datos e os servizos de internet, nun contexto de mercado que presenta un 
alto grao de concentración. Segundo o Instituto Nacional de Educación Tecnolóxica (INETMinisterio de Educación) en Arxentina operan arredor de 12 empresas de telefonía fixa, móbil e transmisión de datos en Internet, xunto a un amplo mercado de pemes que ofrecen principalmente servizos de transmisión de datos. Nun traballo previo identificamos que para o ano 2000, dentro das 1000 empresas de maior facturación do país atopábanse 44 correspondentes ao sector de comunicacións, namentres que once anos despois ese número baixou a 32 (Rodríguez Miglio e Delfini, 2015) o que reflicte a tendencia a unha maior concentración sectorial.

Na economía local operan dúas das maiores compañías internacionais de telefonía: Telefónica de Argentina e Telecom Argentina, filiais dos grupos transnacionais de España e Italia, respectivamente. Ámbalas dúas son no mercado local as dúas maiores empresas do sector, que cara o ano 2005 conservaban o 90\% das liñas telefónicas fixas, ademais de superar o 80\% do negocio de chamadas de longa distancia nacional e internacional (Forcinito, 2005). Ademais, as dúas atópanse na actualidade entre as 10 empresas de maior facturación que operan na economía local (Revista Mercado, 2014).

A distribución por liñas de negocio ao interior do sector exhibe un comportamento diverxente. A telefonía móbil constitúese recentemente no compoñente principal dos ingresos do sector, ao pasar de representar o $38 \%$ das vendas en 2006 , a máis do $70 \%$ en 2014 (Táboa 2). Xunto coa telefonía móbil, aínda que en menor medida, os ingresos relacionados con internet tamén exhiben un franco ascenso nos niveis de participación. A outra cara deste proceso é o retroceso do negocio da telefonía fixa que pasou de representar preto da metade dos ingresos en 2006 a pouco máis do 10\% en 2014.

Táboa 2. Ingresos por vendas e participación por sector en millóns de pesos e porcentual, 2006/ 2014

\begin{tabular}{r|ccccccccc} 
& $\mathbf{2 0 0 6}$ & $\mathbf{2 0 0 7}$ & $\mathbf{2 0 0 8}$ & $\mathbf{2 0 0 9}$ & $\mathbf{2 0 1 0}$ & $\mathbf{2 0 1 1}$ & $\mathbf{2 0 1 2}$ & $\mathbf{2 0 1 3}$ & $\mathbf{2 0 1 4}$ \\
\hline $\begin{array}{r}\text { Total de } \\
\text { ingresos por } \\
\text { vendas }\end{array}$ & 19.890 & 21.155 & 26.780 & 30.120 & 35.913 & 47.165 & 60.612 & 74.364 & 89.756 \\
$\begin{array}{r}\text { Participación } \\
\text { de Telefonía }\end{array}$ & $47,64 \%$ & $32,78 \%$ & $27,07 \%$ & $25,23 \%$ & $22,31 \%$ & $17,62 \%$ & $14,51 \%$ & $12,39 \%$ & $10,12 \%$ \\
Fixa & & & & & & & & & \\
$\begin{array}{r}\text { Participación } \\
\text { de Telefonía } \\
\text { Móbil }\end{array}$ & $38,11 \%$ & $51,05 \%$ & $56,01 \%$ & $57,77 \%$ & $60,56 \%$ & $64,56 \%$ & $67,84 \%$ & $69,95 \%$ & $71,87 \%$ \\
$\begin{array}{r}\text { Participación } \\
\text { de Internet }\end{array}$ & $5,66 \%$ & $7,47 \%$ & $9,34 \%$ & $9,96 \%$ & $10,69 \%$ & $11,81 \%$ & $11,94 \%$ & $12,07 \%$ & $12,40 \%$ \\
$\begin{array}{r}\text { Participación } \\
\text { de Datos e } \\
\text { outros }\end{array}$ & $8,60 \%$ & $8,70 \%$ & $7,58 \%$ & $7,04 \%$ & $6,44 \%$ & $6,01 \%$ & $5,71 \%$ & $5,59 \%$ & $5,61 \%$ \\
\end{tabular}

Fonte: Elaboración propia en base a CICOMRA

En termos físicos, o parque telefónico superou recentemente os 10 millóns de liñas fixas en servizo e acadou máis de 60 millóns de liñas móbiles, é dicir, aproximadamente 1,5 teléfonos móbiles por habitante. O servizo de Internet conta na actualidade con 33 millóns de usuarios de internet e evoluciona a taxas crecentes. A produción de servizos, tanto como a de manufacturas, require para o seu proceso de valorización poñer en actividade as forzas 
humanas do traballo. Pasemos a analizar entón o ocorrido na etapa recente con respecto aos niveis de emprego e salariais.

\section{Emprego, remuneracións e produtividade no sector}

Na produción de telecomunicacións traballan na actualidade arredor de 80 mil persoas rexistradas, distribuídas entre distintas categorías de empregos técnicos, administrativos, loxística e de obra. A mediados da década dos noventa, o emprego no sector daba como media un poco máis dos 50 mil postos de traballo e se atopaba en ascenso. Xusto antes da crise os traballadores rexistrados nas telecomunicacións chegaron a poco máis de 67 mil, pero este número sofreu unha forte contracción entre os anos 2002 e 2003, momento no que se situou por debaixo dos 60 mil postos de traballo (Táboa 3).

O crecemento do emprego no total da economía a partir da saída da crise de 2001 foi acompañado polo crecemento no emprego do sector, pero cun ano de atraso. Entre os anos 2003 e ata o 2008 o emprego rexistrado creceu máis do 30\% acumulado, acadando os niveis actuais de preto de 80 mil postos de traballo. Nembargantes, como se ve na Táboa 3, a recuperación do emprego a partir de 2004 estivo por debaixo do crecemento do emprego de todos os sectores, retrasando cada ano máis a participación no emprego sectorial.

Táboa 3. Postos de traballo rexistrados no sector telecomunicacións , 2001-2013

\begin{tabular}{l|lllcc} 
Ano & Emprego total & Emprego Ss. & $\begin{array}{c}\text { Emprego } \\
\text { Telecom. }\end{array}$ & Telecom./ total & Telecom./ Servizos \\
\hline 2001 & 3.916 .305 & 2.520 .592 & 67.262 & $1,72 \%$ & $2,67 \%$ \\
2002 & 3.519 .482 & 2.310 .777 & 60.760 & $1,73 \%$ & $2,63 \%$ \\
2003 & 3.724 .368 & 2.404 .741 & 59.418 & $1,60 \%$ & $2,47 \%$ \\
3004 & 4.178 .630 & 2.663 .871 & 62.435 & $1,49 \%$ & $2,34 \%$ \\
2005 & 4.687 .445 & 2.967 .830 & 66.751 & $1,42 \%$ & $2,25 \%$ \\
2006 & 5.134 .202 & 3.236 .915 & 71.478 & $1,39 \%$ & $2,21 \%$ \\
2007 & 5.575 .916 & 3.522 .578 & 75.920 & $1,36 \%$ & $2,16 \%$ \\
2008 & 5.914 .439 & 3.762 .976 & 79.689 & $1,35 \%$ & $2,12 \%$ \\
2009 & 5.828 .982 & 3.749 .273 & 79.246 & $1,36 \%$ & $2,11 \%$ \\
2010 & 5.976 .480 & 3.869 .542 & 79.457 & $1,33 \%$ & $2,05 \%$ \\
2011 & 6.262 .634 & 4.044 .409 & 78.343 & $1,25 \%$ & $1,94 \%$ \\
2012 & 6.344 .827 & 4.120 .216 & 78.966 & $1,24 \%$ & $1,92 \%$ \\
2013 & 6.397 .140 & 4.164 .668 & 79.536 & $1,24 \%$ & $1,91 \%$
\end{tabular}

Fonte: Elaboración propia en base a OEDE-MTSS

Así, a participación dos postos de traballo do sector en relación co total dos servizos caeu de $2,67 \%$ antes da crise a 1,91\% na actualidade, namentres que en comparación cos postos de traballo do total da economía a redución na participación evolucionou do 1,72\% ao 1,24\%. Nos dous casos a retracción na participación baixou en torno ao $30 \%$.

Sobre a informalidade laboral, destaca a menor incidencia dos traballadores do sector. Segundo informa o INET en base á información relevada mediante a Enquisa Permanente de 
Fogares (EPH) destaca que o rexistro no sector atinxe en 2009 ao $21 \%$ dos trabajadores, fronte ao 32,3\% do total da economía (INET, 2010).

En termos de remuneracións, os traballadores do sector atópanse dentro dos mellores pagos en relación á media dos traballadores rexistrados do total da economía. En base ao rexistro do Observatorio do Emprego e Dinámica Empresaria (OEDE-MTSS) podemos identificar que ao longo do período o salario medio nas telecomunicacións estivo siempre entre un 50 e un $110 \%$ por enriba do salario medio para o total dos traballadores rexistrados. Unha fenda significativa só superada por algunhas actividades ligadas á produción de petróleo, servizos informáticos ou actividades financeiras. Porén, a tendencia desta fenda foi cara a súa redución. A inicios do período, nos anos previos á crise, o salario das telecomunicacións máis que duplicaba o salario medio, namentres que entre 2001 e 2008 esa diferenza foi diminuíndo, acadando o seu mínimo nese ano, momento no que o salario nas telecomunicacións se atopou apenas nun $52 \%$ por enriba da media. Os anos seguintes recuperaron parcialmente a fenda perdida colocándose en 2013 por enriba da media nun $62 \%$.

Un último elemento para caracterizar o emprego no sector refírese á produtividade laboral entendida como a relación entre o produto xerado e o traballo gastado. A dificultade da medición de volumes físicos nos servizos en xeral, e nas comunicacións en particular oriéntanos cara unha medición en función de valores. Así, da evolución do emprego e o valor agregado desenvolvido anteriormente podemos elaborar, alomenos como proxy, o comportamento da produtividade entendida como a relación entre o traballo necesario e o produto xerado, medido a través da relación entre o valor agregado e a cantidade de obreiros ocupados.

Como observamos na Táboa 4, para o ano 2004 a produtividade no sector expresaba un valor de 157 mil pesos por obreiro ocupado, namentres que para o 2012 esta magnitude incrementouse a 335 mil, é dicir, 178 mil pesos máis que en 2004, un 214\% máis que no comezo do período. O crecemento da produtividade foi constante durante estes anos, pero fundamentalmente ata 2008, momento no que se estancou o crecemento do emprego.

\section{Táboa 4. Produtividade segundo Valor Agregado por Obreiro ocupado, 2004-2012}

\begin{tabular}{c|ccccc} 
Ano & Emprego & VAB* & Produtividade* & Vendas** & Produtividade** \\
\hline 2004 & 62.435 & 9.771 .788 & 157 & 4.397 .000 & 70 \\
2005 & 66.751 & 12.043 .277 & 180 & 5.168 .000 & 77 \\
2006 & 71.478 & 14.532 .343 & 203 & 6.242 .000 & 87 \\
2007 & 75.920 & 17.502 .316 & 231 & 7.637 .000 & 101 \\
2008 & 79.689 & 19.728 .352 & 248 & 8.580 .000 & 108 \\
2009 & 79.246 & 22.198 .826 & 280 & 8.707 .000 & 110 \\
2010 & 79.457 & 23.234 .323 & 292 & 9.844 .000 & 124 \\
2011 & 78.343 & 24.877 .498 & 318 & 12.155 .000 & 155 \\
2012 & 78.966 & 26.485 .472 & 335 & 13.869 .000 & 176 \\
\hline
\end{tabular}

* en miles de pesos a prezos do ano 2004, ** en miles de dólares

Fonte: Elaboración propia en base a INDEC e OEDE-MTSS 
Agora ben, dado que o valor agregado foi tomado da conta de transporte e comunicacións ben podería estar ocorrendo que o primeiro dos subgrupos alterase o cálculo da produtividade estritamente das telecomunicacións. Nas últimas dúas columnas da táboa 4 calcúlase a produtividade sectorial en base ás vendas en dólares do mercado das telecomunicacións. A produtividade así medida amósanos unha evolución crecente, coa mesma tendencia que o cálculo segundo valor agregado, que parte dos 70 mil dólares de vendas por obreiro ocupado e acada os 176 mil cara o ano 2012. O incremento da produtividade aproximada das dúas formas supera o $200 \%$, malia que en termos de VA resulta un pouco menor (213\% fronte a $249 \%$ ), o cal nos indica que a produtividade así medida podería estar sendo subestimada.

A tendencia crecente da produtividade indícanos que na industria das telecomunicacións vén operando un ou algún dos seguintes elementos: i) cambios na organización do traballo, ii) incorporación tecnolóxica e/ ou iii) intensificación do traballo.

En resumo, nesta breve caracterización das telecomunicacións arxentinas observamos que o sector creceu, gañou participación e incorporou postos de traballo de maneira conxunta ata 0 ano 2009, momento no que todas as variables atoparon certo límite ao seu crecemento. Nos últimos anos, a capacidade de xerar postos de traballo paralizouse, a taxa de crecemento do valor agregado baixou considerablemente, caíndo do 19\% entre 2004 e 2008, ao 8\% nos anos seguintes, e a participación no produto total da economía chegou ao seu máximo en 2009, momento no que comezou a gravitar nestes niveis. No interior do sector, a telefonía móbil é o motor dos ingresos que se foi consolidando nos últimos anos.

En termos de emprego, o sector gañou participación en comparación coa década dos noventa, pero chegou a un teito de 80 mil postos de traballo dende 2009. Esta pausa na creación de emprego implicou unha menor participación relativa no emprego total.

A análise do caso que trataremos no seguinte apartado sobre unha das empresas máis relevantes do sector permitirá profundar na caracterización da evolución das telecomunicacións nos anos recentes, ratificando ou matizando algunhas das tendencias identificadas a nivel xeral.

\section{A superación da crise a base da expansión de novos servizos: o caso Telefónica de Argentina}

Nesta sección analizaremos a evolución da empresa Telefónica de Argentina S.A. (TASA) en base á información contida nos balances da compañía 2002-2010 publicados na páxina web da Comisión Nacional de Valores (CNV). TASA é unha empresa de tipo sociedade anónima constituída en Arxentina no ano 19902, cuxo obxecto social é a prestación baixo licenza de servizos de telecomunicación pública por enlace fixo e servizos de telefonía básica no país. Forma parte do grupo Telefónica SA de España (TSA) ${ }^{3}$. Os ingresos da empresa responden fundamentalmente á prestación de servizo telefónico fixo e servizos de internet.

\footnotetext{
2Inicialmente baixo o nome de Sociedad Licenciataria Sur Sociedad Anónima.

3 No 31 de decembro de 2010, a empresa Compañía Internacional de Telecomunicaciones S.A. (COINTEL) era titular do $51,49 \%$ do capital social da Sociedade, sendo o segundo titular máis importante, a empresa Telefónica Móviles de Argentina S.A. (TMA) co 29,56\% do capital social. Outros tres operadores con titulares menores do capital social de TASA: Telefónica Internacional S.A. (TISA, co 16,2\%), Telefónica S.A. (TSA, co 1,8\%) e Telefónica International Holding BV S.A. (TIHBV, co 0,95\%). Os accionistas de COINTEL nesta data eran tamén tres afiliadas de TSA que en conxunto posuían o 100\% do capital accionario de COINTEL. As tres afiliadas son Telefónica International Holding B.V. (TIHBV, cunha participación do 10,01\% do capital total), Telefónica Holding de Argentina S.A. (THA, cunha participación do 47,22\% do capital total), e Telefónica Móviles Argentina Holding S.A. (TMAH, cunha participación do 42,77\% do capital total).
} 
A saída da convertibilidade en 2002 implicou unha forte contracción da actividade que impactou reducindo considerablemente o volume de vendas da empresa. Porén, mediante a redución do gasto, a empresa tivo ganancias negativas tan só no ano 2002. As dúas variables, mesmo considerando a variación dos prezos, amosan niveis significativamente menores nos anos posteriores á crise ${ }^{4}$. Por unha banda, as vendas atópanse nun nivel que representan arredor do $30 \%$ das vendas de media ata o ano 2000, por outra, os gastos, malia que tamén baixaron, fixérono en menor medida, representando preto dun 35\% dos gastos de antes da crise. Como consecuencia deste movemento, a ganancia bruta da empresa baixou sensiblemente.

Gráfico 2. Evolución das vendas e do gasto en millóns de pesos, ano base=2008.

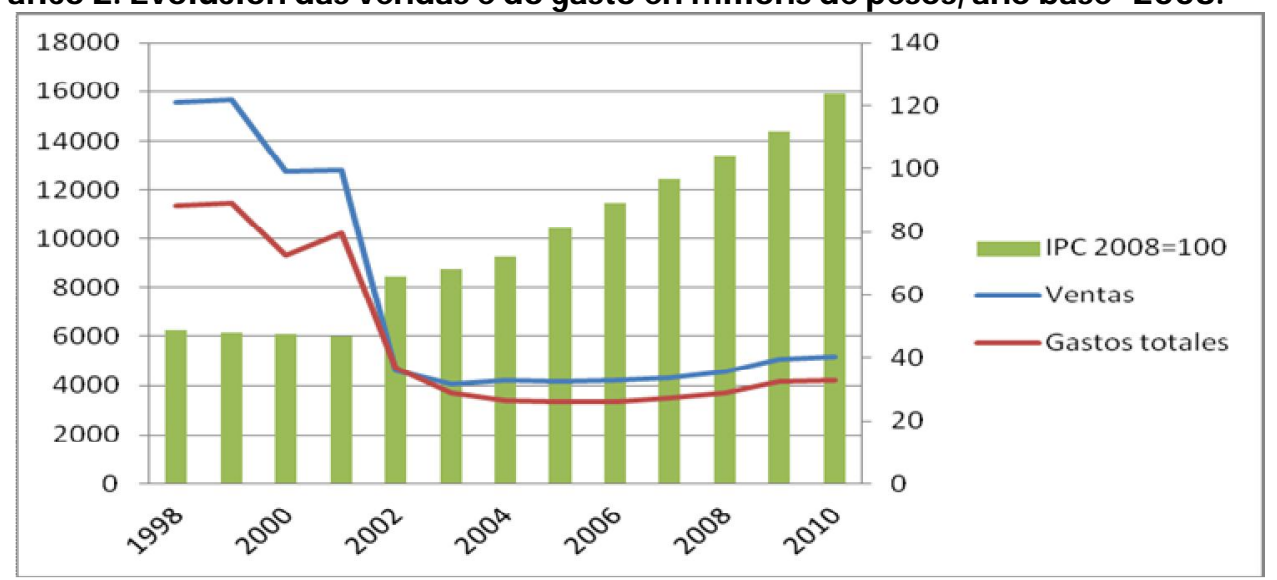

Fonte: Elaboración propia en base a balances da compañía.

Pero antes de adiantar coa evolución da ganancia da empresa, vexamos o que ocorreu co interior dos gastos neste período. Como dixemos anteriormente, o nivel de gasto contraíuse significativamente a partir de 2002. Durante os seguintes anos continuou diminuíndo pero a unha menor velocidade, ata acadar un mínimo no ano 2004. A partir dese momento comezou a aumentar aínda que a pouca velocidade. A información obtida dos balances da compañía permite identificar a composición do gasto en base á discriminación de tres compoñentes: 0 gasto de explotación (gastos directamente referidos ao desenvolvemento da actividade), gastos de administración e gastos de comercialización. A redución do gasto total a partir de 2002 presentou diverxencia en cada un dos compoñentes, modificando a composición do mesmo. Como podemos observar no gráfico 3, antes da crise o compoñente fundamental do gasto referíase á explotación da actividade, que representaba preto do 65\% do gasto total, namentres que os gastos de comercialización constituían o segundo compoñente, con pouco menos do $24 \%$ do total. Os anos seguintes exhiben unha maior contracción deste último tipo de gastos, acadando o seu mínimo peso relativo no ano 2003, por debaixo do 7\% dos gastos totais. A cara oposta desta redución está representada nos gastos de explotación que gañaron participación ata ese ano, acadando pouco menos do $80 \%$ dos gastos totais. Esta tendencia comeza a revertirse lentamente ata que en 2007 a distribución do gasto representa unha composición semellante á de 2001, para despois continuar a profundarse. Así, cara o final do período, os gastos de comercialización colócanse preto do $32 \%$ do gasto total, namentres que os gastos de explotación acadan o mínimo do período, na orde do 57\%.

\footnotetext{
4 En todos os casos corresponde baixar o volume de ganancia segundo un índice de prezos que permita comparar as magnitudes dos distintos anos dado o contexto inflacionario. Neste caso utilizouse o ipc elaborado polo indec con ano base abril de 2008.
} 
Durante toda a serie analizada, o gasto referido á administración evolucionou de maneira correlacionada co gasto total, gravitando arredor dun 13\% dos gastos totais.

\section{Gráfico 3. Composición do gasto en millóns de pesos, ano base=2008.}

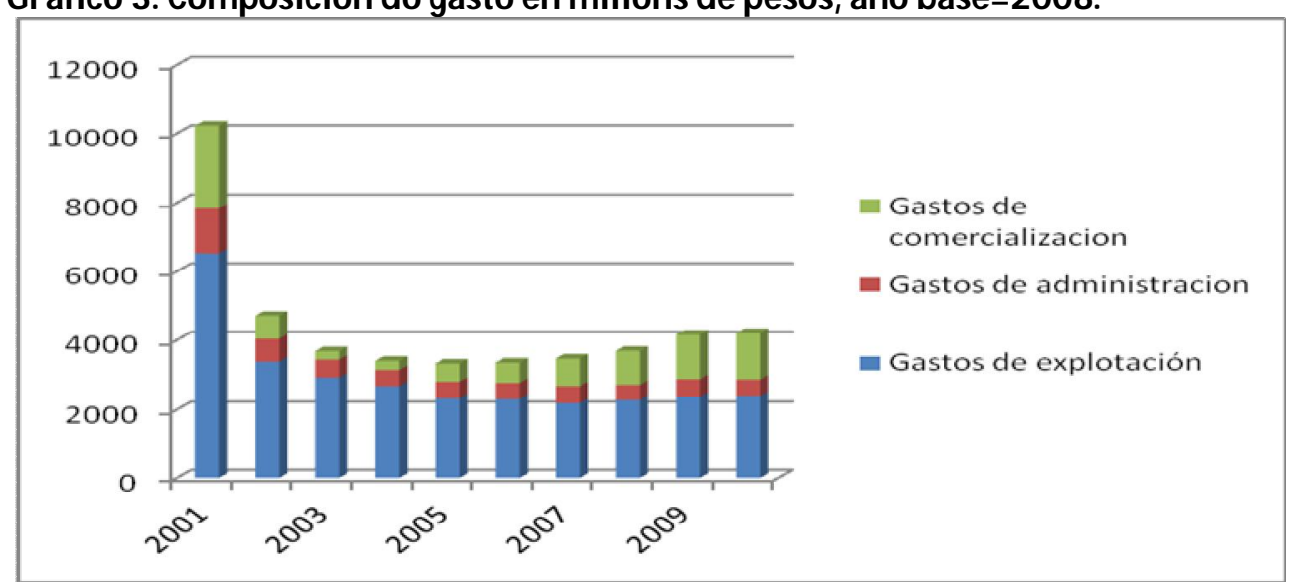

Fonte: Elaboración propia en base a balances da compañía

\section{Gráfico 4. Evolución da masa de ganancia en millóns de pesos, ano base=2008}

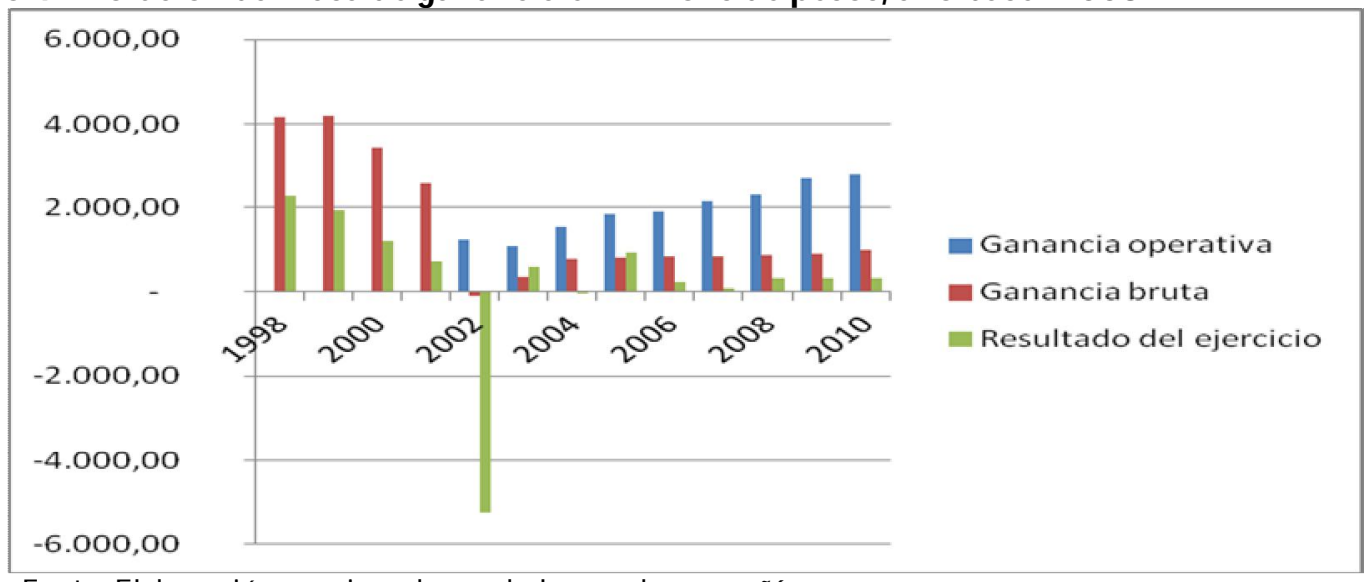

Fonte: Elaboración propia en base a balances da compañía.

A partir da análise de vendas e gastos podemos identificar a masa de ganancia da empresa a distintos niveis. Un primeiro nivel refírese á ganancia operativa da empresa, é dicir, a que xorde estritamente da diferenza entre vendas e gastos de explotación. Un segundo nivel refírese á ganancia bruta, é dicir, a diferenza entre as vendas e os gastos totais da empresa (os seus tres compoñentes). Finalmente podemos analizar a evolución da masa de ganancias da empresa a partir da utilidade total do exercicio, que contempla resultados por investimentos permanentes, operacións discontinuas, resultados financeiros e impostos ás ganancias 5 .

O volume de ganancias coa información contadora amosa a evolución da empresa durante 0 ocaso da convertibilidade, a crise e a posterior recuperación. Os resultados finais dos

5 O volume de ganancias para cada ano tamén foi corrixido segundo o índice de prezos ao consumidor elaborado polo indec con ano base abril de 2008. 
exercicios baixan entre os anos 1998 e 2001, para tornarse significativamente negativos no ano 2002, e recompoñerse dende 2003, pero a niveis marcadamente inferiores aos prezos da crise. Porén, se comparamos os distintos niveis de ganancia da empresa observamos que en termos operativos, a empresa de telecomunicacións non tivo dificultades para operar nin sequera durante a crise (ano 2002), conseguindo unha ganancia operativa positiva, e unha mínima perda en termos de ganancia bruta, é dicir, considerando tamén os gastos administrativos e de comercialización. Polo tanto, o resultado negativo do negocio das telecomunicacións no marco da crise de 2001 refírese principalmente ao ocorrido fóra da actividade específica. Efectivamente dos balances xorde un resultado negativo que corresponde aos resultados financeiros e inusuais superior aos 3.200 millóns de pesos. Polo tanto podemos afirmar que en termos operativos a empresa tanto durante como despois da crise operou coa súa capacidade de xerar ganancias a pleno funcionamiento, mesmo considerando a totalidade dos gastos. Así observamos no grafico 4 que tanto ganancia operativa como bruta presentan valores positivos e crecentes dende 2003.

Nembargantes, este desempeño da masa de ganancia non representa directamente a capacidade deste capital para se reproducir nas condicións normais da economía arxentina. Para iso corresponde analizar a evolución da taxa de ganancia e a súa comparación co resto da economía, tendo en conta que de non obter a taxa media de ganancia, dificilmente consiga soster a súa reprodución como capital individual no marco da competencia, debendo recorrir a algunha fonte de compensación.

A taxa de ganancia dun capital individual refírese á relación entre a masa de ganancias obtidas e o capital adiantado nesa operación e explica a capacidade de valorizarse que posúe, é dicir, de reproducirse como capital e non desaparecer perante a competencia ${ }^{6}$. Segundo Abraham et al. (2010) podemos aproximarnos a esa proporción a partir dos balances das compañías utilizando as utilidades totais, como proxy da ganancia, e o patrimonio neto do período anterior, como proxy do capital adiantado. Porén, en épocas inflacionarias esta operación require a actualización das dúas variables nun mesmo momento, mediante a compensación cun índice de prezos. Esta taxa de ganancias así calculada permítenos identificar a evolución patrimonial da empresa e resulta de suma importancia dende o punto de vista do accionista ou investidor. Isto é así porque contempla os resultados non só da actividade específica das telecomunicacións, senón a participación noutras actividades, por exemplo, de tipo financeiro ou de outras actividades produtivas.

Dado que os noso obxectivo proposto refírese ao estudo sectorial da actividade específica, corresponderá identificar a taxa de ganancia que obtén a empresa pola súa participación concreta na prestación de servizos de telecomunicacións, polo tanto será necesario realizar algunhas modificacións tanto no numerador como no denominador. No canto da utilidade total, calculamos a masa de ganancias como a diferenza entre ingresos por vendas e os custos totais do ano en curso, é dicir, a ganancia bruta. No denominador utilizamos como capital adiantado a suma dos bens de uso, os bens de cambio e os salarios adiantados, todo do período anterior 7 . En Bastida et al. (2014) pódese atopar unha aproximación a esta forma de cálculo.

En base á información obtida nos balances puídose calcular as dúas aproximacións da taxa de ganancia, tanto a patrimonial como pola actividade específica, e foron incluídas no seguinte cadro. Todas as variables utilizadas foron compensadas por un índice de prezos ao consumidor elaborado polo Indec, con base en abril de 2008.

\footnotetext{
${ }^{6}$ Mesmo en sectores con fortes condicións de concentración da produción, a competencia exprésase mediante a necesidade de obter a taxa de ganancia media.

${ }^{7}$ Os salarios adiantados calculáronse en base á masa salarial bruta dividida pola rotación do capital (vendas sobre bens de cambio).
} 
Cadro 4. Taxa de ganancia patrimonial e da actividade de telecomunicacións , 20002010

\begin{tabular}{c|cc} 
Ano & \multicolumn{1}{c}{$\begin{array}{c}\text { Taxa de ganancia } \\
\text { actividade }\end{array}$} & $\begin{array}{c}\text { Taxa de ganancia } \\
\text { patrimonial }\end{array}$ \\
\hline 2000 & s/d & 7,73 \\
2001 & s/d & 5,89 \\
2002 & $-0,77$ & $-202,56$ \\
2003 & 2,96 & 15,11 \\
2004 & 8,46 & $-0,31$ \\
2005 & 11,35 & 29,16 \\
2006 & 14,00 & 11,45 \\
2007 & 16,66 & 3,55 \\
2008 & 20,84 & 12,24 \\
2009 & 22,75 & 13,96 \\
2010 & 28,91 & 15,94
\end{tabular}

Fonte: Elaboración propia en base a balances da compañía.

Ao observar o comportamento da taxa de ganancia nas súas dúas dimensións podemos identificar que no período analizado o negocio específico das telecomunicacións tivo un comportamento favorable á reprodución do capital. Este comportamento é significativamente distinto do que expresa a taxa de ganancia patrimonial. Así, de maneira crecente o resultado da actividade das telecomunicacións supera proporcionalmente ao resultado global da empresa visto a través do seu patrimonio. Isto obsérvase na medida en que a partir de 2006 e para o resto do período a taxa de ganancia da actividade é superior á ganancia patrimonial.

Gráfico 5. Evolución dos determinantes da taxa de ganancia en millóns de pesos, ano base $=\mathbf{2 0 0 8}$

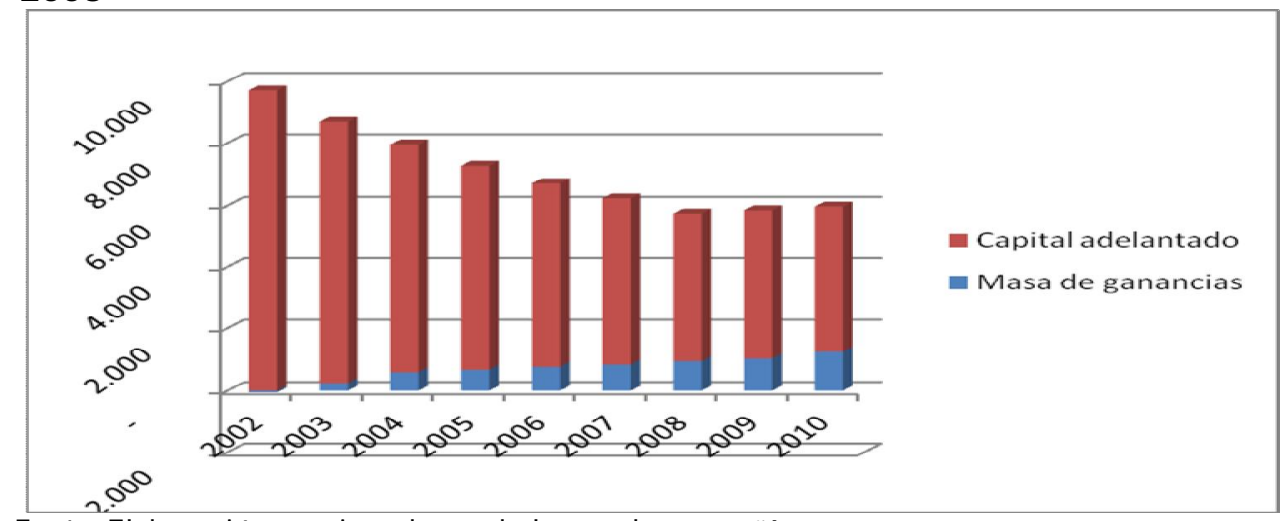

Fonte: Elaboración propia en base a balances da compañía 
O comportamento crecente da taxa de ganancia das telecomunicacións obedece á converxencia dos movementos paralelos. Neste caso, a taxa calculada aumenta tanto pola vía do numerador como do denominador, tanto polo aumento da masa de ganancias obtidas ano tras ano, como pola redución do capital adiantado. Do lado das ganancias xa vimos que o crecemento das vendas superou os gastos totais da actividade. Do lado do capital adiantado, produciuse unha redución constante en todo o período impactando positivamente sobre a taxa de ganancia.

Ao observar esta tendencia á redución do capital adiantado, podemos pensar sobre as cuestións que poderían estar operando neste movemento. Por unha banda, corresponde destacar que o que se está vendo é a información contadora dun capital que ten escindido os seus negocios fundamentais. É dicir, que namentres baixo a forma jurídica de TASA agloméranse os negocios de telefonía fixa e internet, por outra banda, os negocios de telefonía móbil atópanse expresados na información contadora doutra denominación xurídica, Telefónica Móviles.

Porén, dende o punto de vista do proceso de traballo, ben pode ocorrer que certos gastos de funcionamiento se atopen entrecruzados, centralizados ou distribuídos baixo algunha conveniencia contadora ${ }^{8}$. Polo tanto corresponderá estender a presente análise á totalidade das empresas do grupo que operan na economía local. Pero ademais, a forte diminución do capital adiantado (se se corrobora a nivel de grupo económico) estaría amosando indicios de certa descentralización de actividades baixo a forma, por exemplo, de tercerización ou subcontratismo.

Efectivamente, noutros traballos avanzamos na reconstrución do proceso de traballo global mediante a identificación da estrutura de tercerización de actividades de infraestrutura tecnolóxica (Rodríguez Miglio, 2015a). Así mesmo corresponde destacar que, tanto para o sector como para o caso de Telefónica, a tercerización converteuse nunha das principais fontes de conflitividade laboral (Rodríguez Miglio, 2015b) o que reforza a hipótese da redución do capital adiantado pola vía da descentralización produtiva.

Por último corresponde mencionar brevemente a evolución do emprego e as remuneracións da empresa. No momento de iniciar as súas actividades, TASA incorporou unha parte significativa do cadro de traballadores da Empresa Nacional de Telecomunicaciones (ENTEL), nun número superior aos 20 mil postos de traballo. Nos primeiros anos, e por mor dunha serie de reestruturacións, conseguiu diminuír preto dun $17 \%$ do seu cadro de persoal (Ximenez, 1994).

Como se aprecia na táboa 6 , a empresa sofreu unha contracción do emprego entre os anos 2001 e 2003/ 2004 para despois comezar a reverter a tendencia negativa. A dinámica de creación de postos de traballo en TASA acompañou o ocorrido a nivel sectorial, sendo a empresa responsable de preto do $14 \%$ dos postos de traballo do sector ao longo do período analizado, malia que sempre moi por debaixo dos niveis da década dos 90 . Con respecto ao comportamento das remuneracións medias da empresa corresponde destacar unha maior diverxencia con relación ao ocorrido a nivel sectorial. A comezos do período, cara o ano 2001, o salario medio de TASA máis que triplicaba ao salario medio dos traballadores rexistrados do sector telecomunicacións (\$ 1.846.-). Esta fenda foi diminuíndo ata acadar niveis nos que o salario do sector representa preto do $60 \%$ do salario medio no caso analizado (en 2010 o salario medio do sector era de \$6.258.-).

8 Porén, é posible pensar que a dinámica identificada pola empresa TASA sexa a que rexe o negocio global do grupo Telefónica, mesmo cando o motor dos ingresos refírense ao servizo de telefonía móbil, en función de que a masa de empregados resulta significativamente maior aquí que nas compañías de móbiles. 
Táboa 6. Emprego, remuneracións e produtividad en Telefónica, 2001-2010

\begin{tabular}{l|cccc} 
Ano & $\begin{array}{c}\text { Postos de } \\
\text { traballo }\end{array}$ & Salario medio & Liñas en servizo & $\begin{array}{c}\text { Produtividade } \\
\text { física }\end{array}$ \\
\hline 2001 & 9.410 & 6.553 & 4.556 .297 & 484 \\
2002 & 8.998 & 3.964 & 4.419 .162 & 491 \\
2003 & 8.736 & 3.425 & 4.168 .825 & 477 \\
2004 & 8.757 & 3.892 & 4.328 .513 & 494 \\
2005 & 8.898 & 4.186 & 4.534 .844 & 510 \\
2006 & 9.692 & 4.918 & 4.638 .914 & 479 \\
2007 & 10.432 & 5.408 & 4.591 .681 & 440 \\
2008 & 10.708 & 6.747 & 4.605 .723 & 430 \\
2009 & 10.666 & 8.907 & 4.610 .234 & 432 \\
2010 & 10.775 & 10.766 & 4.621 .502 & 429
\end{tabular}

Fonte: Elaboración propia en base a balances da compañía e OEDE-MTSS

Non deixa de resultar chamativo o desempeño da produtividade laboral que xorde de comparar a dotación de persoal da empresa e as liñas en servizo. Este cálculo foi realizado segundo balances sobre a base da telefonía fixa dado que o servizo de internet (ADSL) móntase sobre a mesma estrutura. Neste período a cantidade de liñas en servizo permaneceu relativamente igual, o cual amosa unha produtividade física decrecente produto do incremento dos postos de traballo.

Táboa 7. Produtividade laboral física por Obreiro Ocupado en Telefónica, 2001-2010

\begin{tabular}{|c|c|c|c|c|}
\hline Ano & $\begin{array}{c}\text { Postos de } \\
\text { traballo }\end{array}$ & $\begin{array}{c}\text { Liñas en } \\
\text { servizo }\end{array}$ & $\begin{array}{c}\text { Conexións de } \\
\text { internet }\end{array}$ & $\begin{array}{l}\text { Produtividade } \\
\text { física }\end{array}$ \\
\hline 2001 & 9.410 & 4.556.297 & $\mathrm{s} / \mathrm{d}$ & 484 \\
\hline 2002 & 8.998 & 4.419 .162 & 34.410 & 495 \\
\hline 2003 & 8.736 & 4.168.825 & 69.336 & 485 \\
\hline 2004 & 8.757 & 4.328 .513 & 188.840 & 516 \\
\hline 2005 & 8.898 & 4.534 .844 & 301.902 & 544 \\
\hline 2006 & 9.692 & 4.638 .914 & 515.612 & 532 \\
\hline 2007 & 10.432 & 4.591 .681 & 816.264 & 518 \\
\hline 2008 & 10.708 & 4.605 .723 & 1.078 .966 & 531 \\
\hline 2009 & 10.666 & 4.610 .234 & 1.235 .974 & 548 \\
\hline 2010 & 10.775 & 4.621 .502 & 1.437 .170 & 562 \\
\hline
\end{tabular}

Fonte: Elaboración propia en base a balances da compañía e OEDE-MTSS 
A produtividade así medida caeu entre os anos 2001 e 2010 máis do 10\%, asemade que as vendas creceron e expandíronse novos servizos. Por isto último, permitímonos dubidar da tendencia da produtividade así expresada.

Para tratar de aproximarnos a unha serie de produtividade que reflicta mellor a relación entre produto/servizo e traballo gastado entendemos que corresponde sumar ás liñas de telefonía fixa en servizo, as conexións a internet. Realizando a devandita incorporación na seguinte táboa, a serie de produtividade tórnase crecente agás os anos 2006 e 2007.

A produtividade así estimada, ao noso entender, representa de mellor maneira o que vén ocorrendo na empresa en torno á relación traballo e produto/ servizo e ten o seu correlato co que vén ocorrendo a nivel sectorial na produtividade segundo o valor agregado.

A partir da análise realizada dun capital significativo do sector entendemos que podemos engadir novos elementos para profundar na caracterización feita antes sobre as telecomunicacións arxentinas nos anos recentes. Retomaremos algúns elementos característicos na seguinte sección.

\section{Reflexións finais}

Neste artigo estudamos as telecomunicacións arxentinas na etapa actual. Este sector de actividade creceu, gañou participación e incorporou postos de traballo de maneira conxunta ata 0 ano 2009, amosando certo límite ao seu crecemento dende esa data. Nos últimos anos a capacidade de xerar postos de traballo paralizouse, a taxa de crecemento do valor agregado baixou considerablemente, e a participación no produto total da economía comezou a gravitar nestes niveis.

No interior do sector, a telefonía móbil preséntase como o compoñente dinamizador dos ingresos por vendas. En canto aos traballadores, o sector atópase en niveis salariais que exhiben unha mellor posición relativa con respecto ao resto da economía, malia que esa mellora se vén deteriorando paulatinamente. Perante esta situación cabe preguntarse pola relación existente entre a dinámica salarial do sector e o resto da economía. Quedará para futuras investigacións analizar cales son as mediacións entre os traballadores telefónicos e os sectores non-telefónicos e as súas posibilidades de apropiarse do valor agregado en cada un dos seus espazos de actuación.

Este sector está composto por grandes capitais transnacionais e un universo de pequenas y medianas empresas que en gran medida operan como subsidiarias, provedoras ou intermediarias das grandes empresas do sector. Unha das máis significativas é Telefónica de Argentina que opera a liña de negocios de telefonía fixa e internet de forma directa, e mediante unha empresa asociada, funciona como operador de telefonía móbil. Arrededor dun $14 \%$ dos traballadores do sector atópase en relación directa con Telefónica.

Observar o desempeño deste capital individual permítenos identificar algunhas características do proceso de valorización que ocorre neste sector. Telefónica como capital individual progresou no mesmo senso que o identificado para o sector: evolucionaron as súas vendas, a súa dotación, a súa produtividade, etc. de maneira correlacionada. A diverxencia máis significativa atopámola en relación á remuneración media do sector e da empresa. Xa que existe en Telefónica unha situación relativamente mellor en termos salariais, e considerando a concentración de capital do sector, esta situación concorda coa historicamente establecida entre a distribución salarial e o tamaño das empresas.

A análise particular permite ademais identificar algunhas tendencias propias da dinámica de acumulación de capital. No marco da competencia entre capitais, as unidades produtivas vense empuxadas a substituír obreiros por máquinas. Porén, non toda diminución da dotación implica incorrer nunha maior tecnoloxización do proceso de traballo. A tendencia á 
contracción do cadro de persoal de principios do período obedeceu á necesidade de reducir os gastos por menores ingresos para conseguir a supervivencia do capital nun escenario competitivo9.

Na medida que o volume de traballo se recupera conforme á marcha da economía no seu conxunto, a dotación de persoal volveu aumentar para cubrir as tarefas incrementadas. Nembargantes, ao observarse un achatamento na evolución dos postos de traballo sobre os últimos anos analizados, acompañados do incremento dos ingresos por vendas, cabe a posibilidade de que responda a un maior grao de tecnoloxía incorporada no proceso de traballo. De ser así, a magnitude de capital adiantado debería evolucionar incrementándose. Pero isto non foi así. Telefónica detivo a súa incorporación de persoal no proceso de traballo e diminuíu asemade o volume do seu capital adiantado, impactando positivamente na taxa de ganancia obtida a curto prazo. Este movemento require ser analizado con maior profundidade. Como hipótese de traballo formulamos que, ou ben se redistribuíron tarefas doutros procesos laborais que corresponden a liñas de negocio que non impactan nos rexistros contadores de TASA (por exemplo, telefonía móbil), ou ben que se descentralizaron tarefas en empresas contratistas ou tercerizadas, constituíndo unha complexa estrutura de subcontratación.

Finalmente, e en base á análise do comportamento da taxa de ganancia da empresa, e ao atopar que este capital individual obtivo de media, unha cota proporcional semellante á do capital total para o mesmo período, permitímonos dubidar sobre a efectiva capacidade de exercer, como se afirma en diversos estudos, certo poder de mercado que lle permita obter ganancias extraordinarias pola soa explotación do servizo de telecomunicacións de maneira monopolizada, malia que regulada.

\section{Bibliografía}

Abraham, L., Arelovich, S., Kofman, M. y Perez Barreda, N. (2010) “La inversión bruta fija de las grandes empresas en Argentina: discusión metodológica y comportamiento en el período 1993-2008" III JEC, octubre de 2010. Rosario.

Arelovich, S. (2007) "Aproximaciones a la determinación de la tasa de ganancia" I JEC, octubre de 2007. La Plata.

Azpiazu, D. y Schorr, M. (2010) La industria argentina en la posconvertibilidad: reactivacion y legados del neoliberalismo. Problemas del Desarrollo. Revista Latinoamericana de Economia. Vol. 41, num. 161, abril-junio.

Bastida Bellot, J., Bil, D., Mussi, E. y Seminara, P. (2014) "Rentabilidad en las ramas siderúrgica, autopartista y automotriz argentina durante el período de la ISI a partir de balances (1959-1970)" VII JEC, octubre de 2014. La Plata.

Cámara Argentina de Comercio-CAC (2010) "El rol del sector servicios en Argentina" Publicado en http:// www.acipan.org.ar/ observatorio/web/documentos/a1kd-59relevancia-del-sector-2011.pdf

Cámara de informática y comunicaciones de la República Argentina -CICOMRA (2014) "Informe de mercado de informática y telecomunicaciones" Publicado en http:/ / www.cicomra.org.ar/ cicomra2/ asp/ estadistica nota-sb.asp?id template $=6$

Forcinito, K. (2005) "Estructura y dinámica del mercado de telecomunicaciones en la Argentina. Aportes a la discusión pública sobre regulación” Documentos Plan Fenix. FCE-UBA

${ }^{9}$ Entendemos que a competencia aínda opera en sectores con altos graos de concentración, e cuxo mecanismo se cristaliza na obtención da ganancia media. 
Instituto Nacional de Educación Tecnológica-INET (2010) "Sector telecomunicaciones. Informe Final" Publicado en http:// catalogo.inet.edu.ar/ files/pdfs/info sectorial/ telecomunicaciones-informesectorial.pdf

Iñigo Carrera, J. (2007) “La formación económica de la sociedad argentina”. Buenos Aires, Imago Mundi.

Lavopa, A. y Muller, A. (2009) Regimen macroecónomico y estructura productiva. Novedades y continuidades en la pos-convertibilidad. Congreso Anual AEDA.

Observatorio de Empleo y Dinámica Empresaria-OEDE-MTSS (2013) Boletín de remuneraciones de los trabajadores registrados. Serie anual, Año 2013. Publicado en: http:/ / www.trabajo.gov.ar/ left/ estadisticas/ bel/index.asp

Revista Mercado (2014) Ranking: Las 1000 que más venden. Buenos Aires, Argentina.

Roitter, S., Erbes, A. y Kababe, Y (2010) Desarrollo inclusivo en Argentina: Cambio estructural y empleo en las etapas de recuperación y crecimiento reciente en Hacia un desarrollo inclusivo. El caso de la Argentina, Ricardo Infante y Pascual Gerstenfeld Editores. CEPAL-OIT, Santiago de Chile.

Rodríguez Miglio, M. (2015a) "El proceso (fragmentado) de trabajo en las telecomunicaciones". ASET, agosto de 2015. Buenos Aires, Argentina.

(2015b) "Ciclo económico y protesta laboral en las telecomunicaciones argentinas" VIII Jornadas de Jóvenes Investigadores. Instituto de Investigación Gino Germani, Buenos Aires, Argentina.

Rodríguez Miglio, M., y Delfini, M. (2015) "Los agentes predominantes de la economía argentina" Capítulo en: Recomposición del capital y respuestas sindicales en Argentina ¿Hacia nuevas relaciones laborales? Delfini, M. y Montes Cató, J (comp.) Ediciones UNGS, ISBN 978-987-630-223-4. Los Polvorines, Argentina.

Rodríguez Miglio, M., Roitter, S. y Erbes, A. (2015) "El nuevo trabajo industrial: una mirada critica desde la calidad del empleo" Sociedad y Economía, Revista Nro. 28, ISSN 1657-6357. Universidad del Valle, Calí, Colombia.

Santarcangelo, J., Fal, J. y Pinazo, G. (2011) Los motores del crecimiento económico en la Argentina: rupturas y continuidades. Investigación Económica, Vol. LXX, 275, enero-marzo, pp. 93-114 188 CEPAL

Telefónica de Argentina S.A. (2002-2010) Balances de la compañía. Comisión Nacional de Valores. Publicados en http:// www.cnv.gov.ar/info Financiera.asp?Lang=0

Ximénez Saez, D. (1994) "Privatización y reconversión telefónica: los trabajadores en la mira" En Pensando la Reconversión: una visión crítica de la flexibilidad y la calidad total. CIPES. Publicado en: http:/ / www.tel.org.ar/ spip/ descarga/ plr.pdf

Revista Galega de Economia: http:/ / www.usc.es/ econo/ benvidag.htm https://ideas.repec.org.s/sdo/regaec.html 